\title{
Mengoptimalkan Tugas Pokok Perawat Gigi di Puskesmas (Kajian Tinjauan Pustaka)
}

\author{
I Made Budi Artawa ${ }^{1}$, Ni Nyoman Dewi Supariani ${ }^{2}$, I Nyoman Wirata ${ }^{3}$, A.A. Gd. Agung ${ }^{4}$, I G A \\ Raiyanti ${ }^{5}$ \\ 1,2,3,4,5 Dosen Jurusan Kesehatan Gigi Poltekkes Denpasar \\ Email : imadebudiartawa@gmail.com
}

\begin{abstract}
The main duty of the dental nurse at health center are planning, preparing and doing service of tooth and mouth healthy in individual, group, and society in healthy facility include at health center. Looked on the important of service target achievement of dental and mouth healthy, so the main duty of the dental nurse must be optimal. This unsuccessful show by the national survey result riskedas Bali, that is low number of tooth defence that only reach $42,4 \%$, resident that have care by medical only $1,7 \%$. Konseling care/ clean of the tooth only $12,7 \%$. Besides resident's behavior on caring of the tooth and mouth cleaness is in low number that show by the percentage of the residents that in 10 years old which brushes teeth everyday are 82,2\%, but that brushes their teeth with the right way and time only $16 \%$. Low number of optimalization when do the main duty dental nurse caused by un knowledge the dental nurse of their main duty. Dental nurse, know about their main duty but not do it, and there are no straightening of the regulation. The way to optimalize main duty of dental nurse in the health center are motivate for the next study and serve exercise of dental and mouth healthy to the dental nurse that passed the SPRG, make a rule about do the main duty in the health center, assesmant functional credits number of the dental nurse must be fixed, and doing a meeting between the of PPGI, of PDGI, school institution, health center and Dinkes for talk about the realization of dental nurse's main duty and rebuild the format ricord of dental care service in health center. Optimal of the main duty of dental nurse will support the reach of Millennium Dielopment Goals (MDG's)
\end{abstract}

Keywords: Optimal,main duty, dental nurse, health center, MDG's

Korespondensi: I Md.Budi Artawa, Jurusan Kesehatan Gigi Poltekkes Denpasar, Jl.P.Moyo 33 Denpasar Selatan, 80222, Telp. 0361720084

\section{Pendahuluan}

Arah Pembangunan Bidang Kesehatan Sesuai Pembangunan Nasional, ditujukan pada peningkatan derajat kesehatan melalui peningkatan akses dan mutu pelayanan serta sumber daya manusia.Undang-Undang nomor 36 tahun 2009 tentang kesehatan, menyatakan bahwa penyelenggaraan upaya kesehatan, dalam bidang kesehatan gigi dan mulut dilaksanakan melalui pelayanan kesehatan gigi perseorangan, pelayanan kesehatan gigi masyarakat, dan usaha kesehatan gigi sekolah ${ }^{1}$

Pelayanan kesehatan gigi perorangan, pelayanan kesehatan gigi masyarakat dan usaha kesehatan gigi sekolah merupakan bagian dari tugas pokok Perawat Gigi di Puskesmas. Tugas pokok Perawat Gigi di Puskesmas secara rinci tercantum dalam Keputusan Menteri Kesehatan Nomor 1392/Menkes/SK/XII/ 2001 tentang Registrasi dan Ijin Kerja Perawat Gigi.Perawat Gigi mempunyai Tugas Pokok yaitu merencanakan, mempersiapkan dan melaksanakan pelayanan asuhan kesehatan 
gigi dan mulut pada individu, kelompok dan masyarakat disarana pelayanan kesehatan termasuk Puskesmas ${ }^{2}$

Pelayanan asuhan kesehatan gigi dan mulut sebagai tugas pokok perawat gigi mempunyai tujuan yaitu untuk meningkatkan pengetahuan, sikap dan kemampuan masyarakat untuk berperilaku hidup sehat dibidang kesehatan gigi dan mulut yang mencakup, mampu memelihara kesehatan gigi dan mulut, mampu melaksanakan upaya untuk mencegah terjadinya penyakit gigi dan mulut, mengetahui kelainan-kelainan dalam bidang kesehatan gigi dan mulut, mampu mengambil tindakan yang tepat untuk mengatasinya, mampu menggunakan sarana pelayanan kesehatan gigi yang tersedia secara wajar dan mampu meningkatkan angka mempertahankan gigi. Adapun sasaran pelayanan asuhan kesehatan gigi dan mulut adalah diutamakan kelompok masyarakat yang rentan terhadap penyakit gigi dan mulut. Kelompok tersebut antara lain anak prasekolah, anak sekolah dasar dan ibu hamil $^{3}$

Memperhatikan tujuan dan sasaran pelayanan asuhan kesehatan gigi dan mulut maka tugas pokok perawat gigi tersebut harus dioptimalkan. Namun tujuan tersebut sampai saat ini belum dapat dicapai dengan hasil yang optimal. Ketidakberhasilan tersebut ditunjukkan dengan hasil Riskesdas (2007), yaitusecara nasional prevalensi masalah gigi dan mulut sebesar $23,5 \%$, pengalama karies sebesar 72,1\%, karies aktif sebesar43,4\%. Indeks DMF-T secara nasional sebesar 4,85hal ini menggambarkan bahwa rata-rata kerusakan gigi pada penduduk Indonesia sebanyak lima buah gigi per orang. Komponen yang terbesar adalah gigi dicabut yaitu sebesar 3,86, hal ini menunjukkan ratarata penduduk Indonesia mempunyai empat gigi yang sudah dicabut atau indikasi pencabutan $^{1}$

Hasil survey Nasional Riskesdas Provinsi Bali (2007), menunjukkan masih rendahnya angka mempertahankan gigi hanya mencapai $42,4 \%$,penduduk yang menerima perawatan dari tenaga medis hanya $1,7 \%$. Konseling perawatan/ kebersihan gigi hanya $12,7 \%$. Selain itu pula perilaku penduduk terhadap pemeliharaan kebersihan gigi dan mulut masih rendah yang ditunjukkan dengan persentase penduduk berumur diatas 10 tahun yang menggosok gigi tiap hari sebanyak $86,2 \%$, namun yang menggosok gigi dengan cara yang benar dan tepat waktu hanya $16 \%{ }^{10}$

Ketersediaan tenaga kesehatan gigi berdasarkan data Pusdatin,menunjukkan banyaknya Puskesmas di Indonesia adalah 9.323 buah. Jumlah Dokter gigi sebanyak 8.731 orang dan jumlah Perawat Gigi sebanyak 9.723 orang. Bila dilihat dari penyebaran tenaga kesehatan gigi per Puskesmas maka dokter gigi yang bertugas di Puskesmas sebanyak 6.140 orang dan Perawat Gigi sebanyak 7.685 orang $^{1}$

Perawat Gigi yang tercatat di Persatuan Perawat Gigi Indonesia (PPGI) sebanyak 15.129 orang, dengan penyerapan tenaga $64 \%$ di pemerintahan, $30 \%$ di rumah sakit swasta, klinik swasta dan praktek dokter gigi mandiri, $6 \%$ profesi lain, nganggur dan melanjutkan pendidikan.Jumlah perawat gigi di Provinsi Bali yang tercatat di Persatuan Perawat Gigi Indonesia (PPGI) sebanyak 350 orang, dengan penyerapan tenaga $60 \%$ di pemerintahan, $35 \%$ di rumah sakit swasta, klinik swasta dan praktek dokter gigi mandiri. sebanyak5\% profesi lain, nganggur dan melanjutkan pendidikan. Dari 350 orang perawat gigi, yang sudah menyandang gelah ahli madya kesehatan gigi (lulusan D-III) sebanyak $70 \%^{4}$

Perawat Gigi dengan kaulifikasi pendidikan D-III kesehatan gigi sudah mempunyai kompetensi dan kewenangan untuk melaksanakan tugas pokoknya yaitu pelayanan asuhan kesehatan gigi dan mulut.Namun hasil wawancara dengan perawat gigi yang bertugas di salah satu Puskesmas di Denpasar Barat menyatakan bahwa masih lebih banyak melaksanakan tugas kuratif yang didelegasikan oleh dokter gigi dibandingkan menjalankan tugas pokok 
sebagai Perawat Gigi. Sehingga yang menjadi permasalahan dalam penelitian ini adalah "bagaimanakah cara mengoptimalkan tugas pokok Perawat Gigi di Puskesmas ?.

Tujuan penelitian ini adalah untuk mengetahui faktor yang mempengaruhi optimalisasi tugas pokok Perawat Gigi di Puskesmas dan untuk mengetahui cara mengoptimalkan tugas pokok Perawat Gigi di Puskesmas.Cara penelitian dengan study literature. Adapun manfaat yang diharapkandari penelitian ini adalah untuk meningkatkan pemahaman tugas pokok dalam pelayanan kesehatan gigi dan mulut bagi Perawat Gigidi Puskesmas, dapat dijadikan sebagai bahan pertimbangan dalam membuat kebijakan terutama dalam peningkatan pelayanan kesehatan gigi kepada masyarakat, dan dapat dijadikan pijakan atau masukan untuk penelitian lebih lanjut yang bersifat eksien riset, dan dapat mendukung pencapaian MDG's.

\section{Hasil dan Pembahasan}

\section{Tugas Pokok Perawat Gigi}

Undang-undang Nomor 23 tahun 1992 tentang Kesehatan menjelaskan bahwa untuk mewujudkan derajat kesehatan yang optimal bagi masyarakat, diselenggarakan upaya kesehatan dengan pendekatan pemeliharaan, peningkatan kesehatan (promotif), pencegahan penyakit (preventif), penyembuhan penyakit (kuratif) dan pemulihan kesehatan (rehabilitative) yang dilaksanakan secara menyeluruh, terpadu dan berkesinambungan. Dalam Peraturan Pemerintah Nomor 32 tahun 1992 tentang tenaga kesehatan, dijelaskan bahwa tenaga kesehatan merupakan salah satu unsur penting dalam pelaksanaan upaya kesehatan untuk dapat menyelenggarakan pelayanan yang professional, dan perawat gigi termasuk dalam rumpun keperawatan. Selanjutnya berdasarkan Keputusan menteri Kesehatan Nomor 1392/Menkes/SK/XII/2001 tentang Registrasi dan Ijin Kerja Perawat Gigi, Perawat Gigi mempunyai Tugas Pokok merencanakan, mempersiapkan dan melaksanakan pelayanan asuhan kesehatan gigi dan mulut pada individu, kelompok dan masyarakat disarana pelayanan kesehatan termasuk Puskesmas ${ }^{2}$

\section{Dalam rangka mengarahkan} pelaksanaan tugas pokok Perawat Gigi di Puskesmas maka telah dikeluarkan tata cara kerja pelayanan asuhan kesehatan gigi dan Mulut di Puskesmas, berdasarkan surat keputusan Direktur Jendral Pelayanan Medik Departemen Kesehatan Republik Indonesia Nomor HK. 00.06.4.6.03165. Dalam tata cara kerja pelayanan asuhan kesehatan gigi dan mulut tersebut, dinyatakan dengan jelas bahwa Perawat gigi sebagai salah satu tenaga pelayanan kesehatan gigi dan mulut masyarakat mempunyai tugas pokok antara lain 1) merencanakan pelayanan asuhan kesehatan gigi dan mulut, 2)mempersiapkan kegiatan pelayanan asuhan kesehatan gigi dan mulut, 3) melaksanakan pelayanan asuhan kesehatan gigi dan mulut yang meliputi: a) pengumpulan data, b) upaya peningkatan kesehatan (promotif), c) upaya pencegahan penyakit (prevnetif), upaya penyembuhan terbatas (kuratif), pencatatan pelaporan, evaluasi pelayanan asuhan kesehatan gigi dan mulut ${ }^{5}$

Tujuan pelayanan asuhan kesehatan gigi dan mulut adalah untuk 1) meningkatkan pengetahuan, sikap dan kemampuan masyarakat untuk berperilaku hidup sehat dibidang kesehatan gigi dan mulut yang mencakup a) mampu memelihara kesehatan gigi dan mulut, b) mampu melaksanakan upaya untuk mencegah terjadinya penyakit gigi dan mulut, c) mengetahui kelainan-kelainan dalam bidang kesehatan gigi dan mulut serta mampu mengambil tindakan yang tepat untuk mengatasinya, d) mampu menggunakan sarana pelayanan kesehatan gigi yang tersedia secara wajar. 2) Meningkatkan angka mempertahankan gigi. Adapun sasaran pelayanan asuhan kesehatan gigi dan mulut adalah diutamakan kelompok masyarakat yang rentan terhadap penyakit gigi dan 
mulut. Kelompok tersebut antara lain anak prasekolah, anak sekolah dasar dan ibu hamil $^{5}$

Untuk menjamin mutu dalam pelaksanaan pelayanan asuhan kesehatan gigi dan mulut oleh Perawat Gigi di Puskesmas, maka pada tanggal 21 April 2006 dikeluarkan Surat Keputusan Menteri Kesehatan Nomor 284/Menkes/SK/IV/2006 tentang standar pelayanan asuhan kesehatan gigi dan mulut oleh perawat gigi ${ }^{6}$

\section{Millennium Dielopment Goals (MDG's)}

$\begin{array}{clc}\text { Suzetta dalam sambutannya } \\ \text { menyatakan,di } & \text { penghujung abad lalu, }\end{array}$ Indonesia mengalami perubahan besar yaitu proses reformasi ekonomi dan demokratisasi dalam bidang politik. Tidak begitu lama kemudian, tepatnya pada tahun 2000, para pimpinan dunia bertemu di New York dan menandatangani "Deklarasi Milennium" yang berisi komitmen untuk mempercepat pembangunan manusia dan pemberantasan kemiskinan Komitmen tersebut diterjemahkan menjadi beberapa tujuan dan target yang dikenal sebagai Millennium Development Goals (MDGs).

Pencapaian sasaran MDGs menjadi salah satu prioritas utama bangsa Indonesia. Pencapaian tujuan dan target tersebut bukanlah semata-mata tugas pemerintah tetapi merupakan tugas seluruh komponen bangsa. Sehingga pencapaian tujuan dan target MDGs harus menjadi pembahasan seluruh masyarakat. Walaupun target $M D G s$ sampai tahun 2015, tetapi melihat pencapaian sampai saat ini, Indonesia sepatutnya berbangga hati, karena telah secara nyata mengurangi kemiskinan, dan hampir semua anak laki-laki dan perempuan dapat masuk ke sekolah dasar. Tetapi masih menuntut kerja keras dalam bidang yang lain. Tingginya angka kematian ibu melahirkan dan belum cukup usaha untuk melindungi lingkungan merupakan pekerjaan rumah yang harus diselesaikan secara sungguh-sungguh. Walaupun sudah mencapai banyak kemajuan, tetapi masih diperlukan kerja keras untuk mencapai semua sasaran MDGs.

Tujuan dari MDGs adalah 1) memberantas kemiskinan dan kelaparanEkstrem, 2) Mewujudkan pendidikan dasar untuk semua, 3) Mendorong kesetaran gender dan pemberdayaan perempuan, 4) Menurunkan angka kematian anak, 5 Meningkatkan kesehatan ibu, 6) Memerangi HIV dan AIDS, malaria sertapenyakit lainnya, 7) Memastikan kelestarian lingkungan, 8) Mengembangkan kemitran global untuk pembangunan $^{7}$

\section{Pembahasan}

Tugas pokok Perawat Gigi di Puskesmas tercantum dalam Keputusan Menteri Kesehatan Nomor 1392/Menkes/SK/XII/2001 tentang Registrasi dan Ijin Kerja Perawat Gigi.Perawat Gigi mempunyai Tugas Pokok yaitu merencanakan, mempersiapkan dan melaksanakan pelayanan asuhan kesehatan gigi dan mulut pada individu, kelompok dan masyarakat disarana pelayanan kesehatan termasuk Puskesmas. Memperhatikan pentingnnya pencapaian tujuan pelayanan asuhan kesehatan gigi dan mulut maka tugas pokok perawat gigi tersebut harus dioptimalkan. Adapun tujuan pelayanan asuhan kesehatan gigi dan mulut adalah 1) untuk meningkatkan pengetahuan, sikap dan kemampuan masyarakat untuk berperilaku hidup sehat dibidang kesehatan gigi dan mulut yang mencakup a) mampu memelihara kesehatan gigi dan mulut, b) mampu melaksanakan upaya untuk mencegah terjadinya penyakit gigi dan mulut, c) mengetahui kelainan-kelainan dalam bidang kesehatan gigi dan mulut serta mampu mengambil tindakan yang tepat untuk mengatasinya, d) dan mampu menggunakan sarana pelayanan kesehatan gigi yang tersedia secara wajar. Tujuan yang ke dua adalah untuk meningkatkan angka mempertahankan gigi. Namun tujuan tersebut 


\section{JURNAL KESEHATAN GIGI}

(Dental Health Journal)

Vol. 7 No.2 Agustus 2020

sampai saat ini belum dapat dicapai dengan hasil yang optimal.

Ketidak berhasilan tersebut ditunjukan denganhasil survey nasional riskesdas Provinsi Bali yaitu rendahnya angka mempertahankan gigi hanya mencapai $42,4 \%$,penduduk yang menerima perawatan dari tenaga medis hanya $1,7 \%$. Konseling perawatan/kebersihan gigi hanya $12,7 \%$. Selain itu pula perilaku penduduk terhadap pemeliharaan kebersihan gigi dan mulut masih rendah yang ditunjukkan dengan persentase penduduk berumur diatas 10 tahun yang menggosok gigi tiap hari sebanyak $86,2 \%$, namun yang menggosok gigi dengan cara yang benar dan tepat waktu hanya $16 \%{ }^{1}$

Rendahnya derajat kesehatan gigi dan mulut tersebut disebabkan oleh karena tidak optimalnya perawat gigi menjalankan tugas pokoknya. Hal tersebut disebabkan oleh karena 1) ketidak tahuan perawat gigi terhadap tugas pokoknya. 2) Perawat gigi tahu akan tugas pokoknya namun tidak menjalankan tugas pokok tersebut. 3) kurang adanya penegakan terhadap regulasi yang ada berkaitan dengan pelaksanaan tugas pokok perawat gigi.

Adapun cara mengoptimalkan tugas pokok perawat gigi di Puskesmas adalah dengan mengatasi penyebab yang ada yaitu :

Penyebab pertama ketidak tahuan perawat gigi terhadap tugas pokoknya. Tidak semua perawat gigi tahu dengan tugas pokonya, hanya perawat gigi yang sudah lulus D-III yang mengetahui dan mampu menjalankan tugas pokok yaitu pelayanan asuhan kesehatan gigi dan mulut. Untuk mengatasi masalah tersebut maka perlu dilakukan pendidikan lanjut kepada perawat gigi yang bertugas di Puskesmas yaitu ke DIII Keperawatan Gigi. Selain pendidikan lanjut bisa juga dilakukan pelatihan pelayanan asuhan kesehatan gigi bagi perawat gigi yang masih lulusan SPRG.

Penyebab kedua,Perawat Gigi tahu akan tugas pokoknya, namun tidak menjalankan tugas pokoknya.Perawat gigi lulusan D-3 masih ada yang tetap menjalan tugas pendelegasian wewenang dibandingkan dengan menjalankan tugas pokoknya, hal ini disebabkan oleh karena ada keengganan untuk tidak menjalankan tugas yang diperintahkan oleh dokter gigi, dan juga tidak merasakan adanya tuntutan/keharusan untuk menjalankan tugas pokoknya. Adapun solusi yang dapat ditempuh untuk mengatasi masalah tersebut adalah dibuatkan kebijakan kepada petugas kesehatan gigi (Dokter Gigi maupun Perawat Gigi) yang ada di Puskesmas agar semua dapat mengetahui dan menjalankan tugas pokoknya. Disamping itu pula agar penilain angka kridit fungsional perawat gigi benarbenar diterapkan.

Penyebab ketiga, kurang adanya penegakan terhadap regulasi yang ada. Tata cara pelayanan asuhan gigi dan mulut di Puskesmas oleh Perawat Gigi sudah ada sejak tahun 1995, namun hasil penelitian ${ }^{8}$ Artawa di Kabupaten Bangli dari sembilan Puskesmas hanya satu Puskesmas yang mempunyai pedoman tersebut.Dan bila diperhatikan pada format pelaporan tentang pelayanan kesehatan gigi dan mulut kurang menggambarkan pelaksanaan tugas pokok dari Perawat Gigi.

Solusi untuk mengatasi masalah tersebut adalah perlu dilaksanakan duduk bersama untuk pembahasan pelaksanaan tugas-tugas pokok sebagaimana tercantum dalam pedoman tersebut. Dan juga menambahkan format pelaporan kesehatan gigi yang mengambarkan pelaksanaan tugas pokok perawat gigi. Duduk bersama dilakukan antara wakil profesi persatuan perawat gigi Indonesia (PPGI) Bali, wakil profesi Persatuan Dokter Gigi Indonesia (PDGI)Bali,institusi pendidikan Keperawatan Gigi Poltekkes Denpasar dan kepala Puskesmas sertaPejabat Dinas Kesehatan.

Apabila solusi tersebut dapat dijalankan dengan baik, maka pengoptimalan tugas pokok perawat gigi dapat dilakukan. Dan jika perawat gigi dapat menjalankan tugas pokoknya dengan optimal maka menunjukkan bahwa upaya pelayanan kesehatan gigi yang 
baik. Menurut Kementerian ${ }^{1}$,upaya pelayanan kesehatan gigi yang baik dapat mendukung pencapaian tujuan MDGs. Tugas pokok perawat gigi dapat dilaksanakan dengan optimal maka akan dapat mendukung percepatan Pencapaian MDGs 2015. Adapun dukungan tersebut dapat dijelaskan sebagai berikut :

Tujuan 1 memberantas kemiskinan dan kelaparan

Sakit gigi, infeksi gigi dan mulut, serta ompong atau tidak mempunyai gigi geligi maka akan mempengaruhi fungsi gigi yaitu pengunyahan makanan yang tidak sempurna. Pengunyahan yang tidak sempurna akan mengarah pada malnutrisi. Masalah gigi dan mulut juga berpengaruh terhadap kehadiran pekerja/pegawai. Akibat dari gigi yang bermasalah menyebabkan pegawai/pekerja tidak optimal melakukan pekerjaannya sehingga berdampak pada kehilangan penghasilan serta terimbas akan kebutuhan biaya untuk perawatan gigi.Apabila tugas pokok perawat gigi dilaksanakan dengan optimal maka derajat kesehatan gigi masyarakat Indonesia akan menjadi lebih baik. Dengan kesehatan gigi yang baik maka akan dapat memberantas kemiskinan dan kelaparan.

Tujuan 2 mencapai pendidikan dasar universal

Masalah gigi yang terjadi pada gigi murid menyebabkan tidak hadir sekolah dan mempunyai efek terhadap konsentrasi belajar. Apabila tugas pokok perawat gigi dalam memberikan pelayanan asuhan kepada anak prasekolah maupun anak sekolah dasar dapat dijalankan dengan optimal maka proses belajar anak tidak akan tetrganngu oleh karena sakit gigi, sehingga akan dapat mempercepat pencapaian tujuan MDGs yaitu pendidikan dasar universal.

Tujuan 3 Mendorong kesetaraan gender dan pemberdayaan perempuan

Para ibu harus mengetahui cara memelihara kebersihan gigi dan mulut bagi kesehatan anaknya. Salah satu sasaran pelayanan asuhan kesehatan gigi dan mulut sebagai tugas pokok perawat gigi adalah meningkatkan pengetahuan ibu dalam memelihara kesehatan gigi dan mulut. Apabila tugas pokok ini dapat dilaksanakan dengan optimal maka akan dapat mempercepat pencapaian tujuan MDGs yaitu mendorong kesetaraan gender dan pemberdayaan perempuan.

Tujuan 4 Mengurangi angka kematian anak

Hal ini terkait dengan Infeksi gigi, NOMA (gangrenous stomatisis) yang dapat berpengaruh terhadap kematian.

Tujuan 5 Memperbaiki kesehatan ibu hamil

Kesehatan gigi dan mulut yang buruk pada ibu hamil mempunyai efek terhadap kelahiran dan berat badan bayi dan juga berdampak pada kesehatan gigi dan mulut bayi nantinya. Salah satu sasaran pelayanan asuhan kesehatan gigi dan mulut sebagai tugas pokok perawat gigi adalah ibu hamil. Apabila tugas pokok ini dapat dilaksanakan dengan optimal maka akan dapat mempercepat pencapaian tujuan MDGs yaitu memperbaiki kesehatan ibu hamil.

Tujuan 6 memberantas HIV/AIDS, dan penyakit-penyakit lainnya

HIV/AIDS dengan kesehatan gigi dan mulutmempunyai hubungan yang erat. Permasalahan yang ditemukan dalam rongga mulut dapat menjadi indikator dini infeksi HIV/AIDS

Tujuan 7 meyakinkan keberlangsungan lingkungan hidup

Penanganan kesehatan gigi dan mulut yang melibatkan penggunaan teknologi yang sesuai, kontrol infeksi yang efektif serta pembuangan limbah medis yang aman.

Tujuan 8 Membangun kerjasama global untuk perkembangan

Kerjasama dalam upaya mempromosikan kesehatan gigi dan mulut diantara para stakeholder.

\section{Simpulan}

Masih rendahnya derajat kesehatan gigi dan mulut Penduduk Indonesia pada 
umumnya dan Penduduk Provinsi Bali khususnya, yang disebabkan oleh karena kurang oftimalnya pelaksanaan tugas pokok perawat gigi. Kurang optimalnya pelaksanaan tugas pokok perawat gigi disebabkan oleh karena ketidak tahuan perawat gigi terhadap tugas pokoknya. Perawat gigi tahu akan tugas pokoknya namun tidak menjalankan tugas pokok tersebut. Dan kurang adanya penegakan terhadap regulasi.

Adapun cara mengoptimalkan tugas pokok perawat gigi di Puskesmas adalah dengan cara memotivasi untukmengikuti pendidikan lanjut dan juga pelatihan pelayanan asuhan kesehatan gigi dan mulut kepada perawat gigi yang masih lulusan SPRG. Dibuatkan kebijakan tentang pelaksanaan tugas pokok Perawat Gigi Puskesmas. Penilain angka kridit fungsional perawat gigi benar-benar diterapkan, dan duduk bersama dilakukan antara wakil profesi persatuan perawat gigi Indonesia (PPGI), wakil profesi Persatuan Dokter Gigi Indonesia (PDGI), institusi pendidikan dan kepala Puskesmas dan Pejabat Dinas Kesehatan untuk membahas pelaksanaan tugas-tugas pokok perawat gigi serta pembaharuan format pelaporan pelayanan kesehatan gigi di Puskesmas. Pelaksanaan tugas pokok perawat gigi yang optimal akan dapat mendukung pencapain tujuan MDGs.

\section{Saran}

Kepada peneliti berikut yang akan melakukan penelitian tentang tugas pokok perawat gigi agar melaksanakan penelitian dengan metode eksien riset dalam rangka meningkatkan derajat kesehatan gigi dan mulut masyarakat Indonesia pada umumnya dan masyarakat Bali pada khususnya.

\section{Daftar Pustaka}

$\begin{array}{lcr}\text { 1. Kementerian } & \text { Kesehatan } & \text { RI., } \\ 2011, \text { Kebijakan } & \text { dan } & \text { Strategi }\end{array}$ Pengembangan Gigi dan Mulut pada Pelayanan Publik, Dirjen Bina Upaya Kesehatan, Jakarta
2. Departemen Kesehatan RI., 2001, Surat Keputrusan Menteri Kesehatan tentang Registrasi dan Ijin Kerja Perawat Gigi, Jakarta

3. Departemen Kesehatan RI., 1995, Tata Cara Pelayanan Asuhan Kesehatan Gigi dan Mulut di Puskesmas, Direktorat Kesehatan Gigi, Jakarta

4. PPGI DPD Bali, 2010, Laporan Pertanggungjawaban PPGI DPD Bali 2008-2010, PPGI DPD Bali, Denpasar

5. Departemen Kesehatan RI., 2006, Kebijakan Dasar Pusat Kesehatan Masyarakat, Depkes RI, Jakarta.

6. Departemen Kesehatan RI., 2006, Standar Pelayanan Asuhan Kesehatan Gigi dan Mulut, Depkes RI, Jakarta

7. Departemen Kesehatan RI., 2007, Standar Profesi Perawat Gigi, Depkes RI, Jakarta

8. Stalker Peter, 2008, Kita Suarakan MDGs Demi Pencapaiannya di Indonesia, http://www.leat speak Out for MDGs.com/id.pdf. 07-04-2012.

9. Artawa, I. M.B, 2008, Analisis Faktor yang Mempengaruhi Permintaan Masyarakat terhadap Pelayanan Kesehatan Gigi Preventif di Puskesmas Bangli , Tesis, Program Pasca Sarjana Magister Manajemen Pelayanan Kesehatan Gigi UGM, Yogyakarta

10. Dinkes.Prov.Bali,2011, Seluruh Puskesmas di Bali Memiliki Klinik VCT, http:// www. selebzone. com/dinke-bali-2011-selu. 07-042012. 
